\title{
Production of polyhydroxybutyrate from oil palm empty fruit bunch (OPEFB) hydrolysates by Bacillus cereus suaeda B-001
}

\begin{abstract}
Polyhydroxybutyrate (PHB) is a biodegradable polymer accumulated in intracellular granules by numerousbacteria. Its physical and chemical characteristics are like those of petrochemical plastics. PHB is producedmainly by gram-negative bacteria such asRalstonia eutropha, which have lipopolysaccharides that co-purify withthe PHB and cause immunogenic reactions, limiting their use for biomedical applications. PHB produced fromgram-positive bacteria such asBacillus spp.do not have lipopolysaccharides, which makes it suitable for bio-medical application. The aim of this work was to evaluate the ability ofBacillus cereus suaedaB-001 to accu-mulate PHB using oil palm empty fruit bunch (OPEFB) hydrolysate as the sole carbon source, comparing it tocommercial glucose as the control. OPEFB was chemically pre-treated using an acid-hydrolysed process bysulphuric acid and neutralized by a $\mathrm{NaOH}$ solution to obtain reducing sugars. PHB biopolyester accumulated to $43.1 \%$ of cell dry weight with glucose at $15 \mathrm{~g} / \mathrm{L}$ as the sole carbon source, and PHB accumulated to $55.4 \%$ of celldry weight using OPEFB hydrolysates at $20 \mathrm{~g} / \mathrm{L}$. The conversion of OPEFB acid hydrolysates to PHB using thegram-positive bacteriaBacillus cereus suaedaB-001 has not been reported.
\end{abstract}

Keyword: Polyhydroxybutyrate; Oil palm empty fruit bunch; Bacillus cereus suaeda B-001; OPEFB acid hydrolysate 